\title{
In Memoriam: Prof. Dr. Wolfgang Friedrich Wülker
}

\author{
Paraskeva Michailova ${ }^{1}$, Jon Martin² and Malcolm G. Butler ${ }^{3}$ \\ ${ }^{I}$ Institute of Biodiversity and Ecosystem Research, Bulgarian Academy of Sciences. \\ ${ }^{2}$ Genetics, Genomics and Development, School of Biological Sciences 5, University of Melbourne, \\ Australia.Email:.j.martin@unimelb.edu.au
}

${ }^{3}$ Biological Sciences Department, North Dakota State University, USA.

With great regret and our sincerest sympathies we announce that our best friend and colleague Prof. Dr. Wolfgang Wülker passed away on January 12 , 2017 at the age of 91 . We lost a scientist who has made valuable contributions to morphological and karyological systematics of the Chironomidae. As an early leader in bringing cytological evidence to bear on the systematics of Northern Chironomus, he combined banding patterns of salivary gland chromosomes with detailed morphological analyses of larvae, pupae, and male imagos. Prof. Wülker authored or participated in many descriptions and revisions of Chironomus species, including extending the Standard chromosome maps of H.-G.Keyl to cover the rather difficult chromosome arms B, C, and D. He also made important contributions concerning the karyotypes, morphology, ecology and distribution of the genera Sergentia and Diamesa. Besides the dozens of precisely written papers with elaborate chironomid chromosome pictures, Dr. Wülker also published many seminal articles on chromosome evolution and phylogeny (Martin and Hoffrichter 2010) ${ }^{1}$. Prof. Wülker worked not only with karyosystematics of European chironomids, but also with Chironomidae in America and Africa. Working with Siberian specialists, he found endemic African banding patterns in the polytene chomosomes of African Chi-

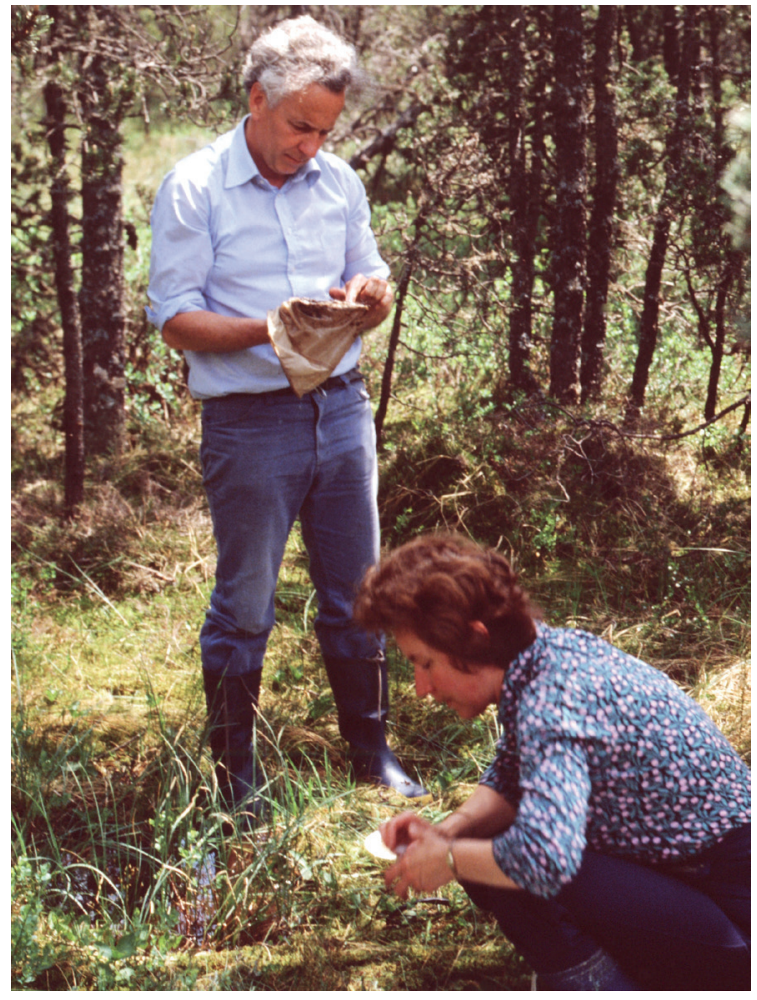

Prof. Wolfgang Wülker and his long-time research assistant Fr. Renate Rössler seek larvae of the phylogenetically basal species Chironomus holomelas in a raised bog (Hochmoor) in Jura, Switzerland, May 1981. Photo: Malcolm G. Butler. ronomus, while documenting that "basic" banding patterns of polytene chromosomes occur in Chironomus species from different continents.

The following example illustrates the broad range of Prof. Wülker's interests in the natural sciences, as well as the potential of any scientific advance to have unanticipated ramifications. Influenced partly by his father's brief career in parasitology, Prof. Wülker conducted numerous investigations on chironomid parasites, particularly the effects of mermithid nematodes on adult chironomid morphology. To understand how parasites altered larval development, Prof. Wülker recognized the need to better understanding the developmental process in normal larvae. His collaboration with P. Götz produced a detailed documentation of imaginal disk development in C. riparius, as pupal and imaginal structures take form during the final instar. The nine "developmental phases" defined by Wülker \& Götz over the course of the $4^{\text {th }}$ instar in Chironomus provided a much more precise tool for the investigation of chironomid larval development. The Wülker \& Götz developmental scheme has been used extensively in diverse studies involving Chironomidae, ranging from genetics and physiology, to life history analysis and biomonitoring of environmental pollution.

${ }^{1}$ One additional paper was published after 2010: Wülker, W.F., Kiknadze, I.I., Istomina, A.G. 2011. Karyotypes of Chironomus Meigen (Diptera: Chironomidae) species from Africa. - Comp. Cytogen 5: 23-46. doi: https://doi.org/10.3897/compcytogen.v5i1.975 
Throughout his long research career Prof. W. Wülker developed fruitful collaborations with many specialists in countries throughout the world (Australia - Prof. J. Martin; USA- Prof. M. Butler, Prof. J. Sublette and his wife M. Sublette; Russia- Prof. I. I. Kiknadze and her team ("the Russian ladies" as he liked to refer to them); Hungary - Prof. G. Devai; Bulgaria- Prof. P. Michailova; Switzerland - Profs. H. M. Ryser and A. Scholl). Publications with these and many other international colleagues produced important contributions to our understanding of the genetics of natural chironomid populations and evolution within the important genus Chironomus, long before the current age of molecular sequencing techniques. Throughout most of the 20th Century, cytogenetic analysis of polytene chromosomes was not only a valuable taxonomic tool for the important genus Chironomus, it also provided great insight into broader topics like genetic differentiation of isolated populations and the role of chromosomal rearrangements in population adaptation, divergence, and speciation. Prof. W. Wülker's work contributed directly to these themes, and greatly facilitated advances made by many others.

Prof. Dr. Wolfgang Wülker has been one of the most active participants in the International Chironomid Symposia. Present at the First Symposium held in Plön, Germany in 1964, Prof. Wülker hosted the 13th Symposium at Freiburg in September 1997. Though unable to attend the 2003 Symposium in person, he presented - by video recording - the Thienemann honorary lecture at the 15th International Chironomid Symposium in Minneapolis, USA. His address on "The Role of Chromosomes in Chironomid Systematics, Ecology and Phylogeny" was an insightful overview of the many ways in which cytogenetic studies have enhanced our knowledge of chironomid taxonomy, genetics, ecology, evolution, and biogeography.

We express our deepest grief on the death of our dear colleague and collaborator. We will miss his friendship, competence and advice.

\section{References}

Martin, J., Hoffrichter, O. 2010. Wolfgang Friedrich Wülker, on the occasion of his 85th birthday. - Chironomus Newsletter on Chironomidae Research 23: 4-9.

Pepi Michailova, Jon Martin and Malcolm Butler 